Acta Cryst. (2002). A58 (Supplement), C123

\section{HAIRPIN TURNS AND POLAR $\beta$-SHEET ASSEMBLY BY PEPTIDES CONTAINING $\beta$-AMINO ACID RESIDUES}

\section{Karle ${ }^{1}$ P. Balaram ${ }^{2}$}

${ }^{1}$ Naval Research Laboratory Laboratory for The Structure of Matter, Code 60304555 Overlook Avenue, S.W. WASHINGTON D.C. 20375-5341 USA ${ }^{2}$ Molecular Biophysics Unit, Indian Institute of Science, Bangalore, India

Hexa- to deca-peptides, designed with the inclusion of several $\beta$-amino acids in their sequences, make hairpin turns and $\mathrm{C}=\mathrm{O}$...HN hydrogen bonds between the antiparallel strands of the backbone. A centrally placed d-Pro-Gly segment in a sequence of hydrophobic residues has been shown to facilitate $\beta$-hairpin formation. The peptides containing $\beta$-residues have been designed with $\beta$ residues facing each other across the strands. The manner of hairpin formations is similar to that observed in hairpins containing only $\alpha$-amino acid residues. The differences in the types of hairpins are extra 'pleats,' seen when the hairpin is viewed from the side, that reflect the additional length of the backbone in a $\beta$-residue. More important is the formation of polar areas in the hairpin and the extended pleated $\beta$-sheet, caused by the alignment of $\mathrm{C}=\mathrm{O} \ldots \mathrm{HN}$ bonds in the same direction between strands, instead of alternating directions as in hairpins made with all $\alpha$ residues. Crystal structures of (a) Boc-beta-Phe- $\beta$-Phe-d-ProGly-beta-Phe-beta-Phe-OMe, an all $\beta$-peptide except at the hairpin turn; (b) Boc-Leu-Val- beta-Val-d-Pro-Gly-beta-Leu-Val-Val-OMe with mixed $\alpha$ - and $\beta$ - residues and (c) Boc-Leu-Val-beta- Phe-Val-d-Pro-Gly-Leu-beta-Phe-ValVal-OMe with mixed $\alpha$ - and $\beta$ - residues show fully hydrogen- bonded infinite $\beta$-sheets that differ from each other and differ in the extent of the polar areas, depending upon the placement of the $\beta$-residues in the sequence. Attempts to construct $\beta$-hairpins with longer strand lengths exclusively composed of $\beta$-Phe residues resulted in peptides with extremely poor solubility.

\section{Keywords: $\beta$ PEPTIDES, $\beta$ HAIRPINS, POLAR $\beta$ SHEETS}

Acta Cryst. (2002). A58 (Supplement), C123

CONFORMATIONAL CHACARTERISTICS OF 40 STEROID COMPOUNDS BEFORE AND AFTER MOLECULAR MECHANICS CALCULATIONS

$\underline{\text { S. Stankovic }}^{1}$ D. Lazar ${ }^{1}$ O. Markovic ${ }^{1}$ K. Penov Gasi ${ }^{2}$ J. Petrovic ${ }^{2}$ R. Kovacevic $^{3}$ T. Pilati ${ }^{4}$ Ch. Courseille ${ }^{5}$

${ }^{1}$ Faculty of Sciences, University of Novi Sad Institute of Physics Trg Dositeja Obradovica 4 NOVI SAD 21000 YUGOSLAVIA ${ }^{2}$ Institute of Chemistry, Faculty of Sciences, University of Novi Sad ${ }^{3}$ Institute of Biology, Faculty of Sciences, University of Novi Sad ${ }^{4}$ Istituto di Scienze e Technologie Molecolari, CNR, Milano ${ }^{5}$ Unte de Biophysique Structurele, Universite Bordeaux

Comparison of structural features of 40 steroids before and after molecular mechanics calculations is given. All compounds were synthesised, solved and analysed by our group. The compounds belong to estrogens and androgens, with different substituents predominantly connected with $\mathrm{C} 17$ atom. About a half of them are 16,17-seco estrogens (androgens). For ten of them, which are unpublished, the main structural characteristics will be presented.

The overall conformational analysis of all 40 compounds was performed before and after molecular mechanics calculations, showing the degree of rigidity of steroid malecules. Comparative analysis is performed in order to correlate molecular conformation and biological function of steroids. The results obtained confirm the substantial rigidity of steroid molecules. The conformation of steroids having flexible unsaturated ring and/or substituents were of particular interest. The attention was paid to the degree of rotation of C17-sustituents (specially the bulky ones) around single bond, due to the intention of our group to alter biological activity of steroids by changing the C17 substituents to achieve and reinforce their antiestrogenic and antiandrogenic effects. The energy minima of the molecules before and after mmc, and energy barriers for free rotation were calculated. The variety of hydrogen-bond pattern in the compounds under examination will be presented, too.

Keywords: STEROIDS, MOLECULAR MECHANICS, STRUCTURE ACTIVITY RELATIONSHIPS
Acta Cryst. (2002). A58 (Supplement), C123

CRYSTAL AND MOLECULAR STRUCTURE OF THE ANTIBIOTIC/ANTITUMOR COMPOUND TAUROLIDINE

M. Rossi ${ }^{1}$ E. Simms ${ }^{1}$ F. Caruso ${ }^{2}$

${ }^{1}$ Vassar College Chemistry Dept. Box 484 POUGHKEEPSIE NY 12604-0484 USA ${ }^{2}$ Istituto di Strutturistica Chimica, CNR, Monterotondo Stazione (Rome)00016, Italy

The structure of taurolidine, a broad spectrum antibiotic with anticancer potential, was determined by using single crystal X-ray diffraction techniques and solved by direct methods. The crystals are triclinic and crystallize in space group P-1, with two molecules in the asymmetric unit. The unit cell dimensions are: $a=10.892(7) \AA, b=9.178(5) \AA, c=13.916(9), \alpha=87.36^{\circ}(2), \beta=69.77^{\circ}$ (2), $\gamma=70.03^{\circ}(2)$. The structure was refined to a final $\mathrm{R}=0.065$. The molecules in the asymmetric unit have slightly different conformations, associated mainly with rotation about the central N-C bonds. Molecular mechanics techniques to determine the difference in conformational energy between the two molecules were applied. A slight difference was observed in the two crystallized conformations at room temperature. The main difference in rotation between the two conformers is also the point at which the molecule is hydrolyzed upon contact with aqueous media. This structural breakdown of the drug is necessary for the exhibition of antibacterial and probably, its antitumor activity.

Keywords: ANTIBIOTIC, ANTITUMOR, CRYSTAL STRUCTURE
Acta Cryst. (2002). A58 (Supplement), C123

X-RAY CRYSTAL AND MOLECULAR STRUCTURE OF 16-(4CYNOBENZYLIDENE)-3-PYRROLIDINO-5-ANDROSTEN-17-OL MONOHYDRATE

S. Thamotharan R. Hema V. Parthasarathi S. Dubey D.P. Jindal Bharathidasan University Department of Physics TIRUCHIRAPPALLI TAMIL NADU 620024 INDIA

In the title compound the outer six-membered rings are in chair conformations, while the central ring is in an $8 \beta, 9 \alpha$-half chair conformation. The five membered ring adopts a $13 \beta$-envelope. The steroid nucleus is linked by intermolecular hydrogen bonds to form a molecular network. The molecular packing has an interesting feature with the steroids aligned parallel to b-axis forming a closed loop through hydrogen bonds linked via water molecules.

\section{Keywords: STEROIDS, ANDROGEN RECEPTORS,CHAIR CONFORMATION}

